\title{
Motivational Strategies in EFL Classrooms And their Feasibility in Iraqi Context
}

\author{
Selcuk Koran \\ Ishik University, Iraq \\ E-mail: selcuk.koran@ishik.edu.iq
}

Received: 24-08- 2014

Published: 01-05- 2015
Accepted: 01-12- 2014

doi:10.7575/aiac.ijalel.v.4n.3p.45
Advance Access Published: December 2014

URL: http://dx.doi.org/10.7575/aiac.ijalel.v.4n.3p.45

\begin{abstract}
Teachers are seen as the major determinant sources of motivation for language learners. Moreover, teachers are expected to enhance learners' motivation for better language learning since the positive effect of this relationship on the students' achievement has been proved in many studies. Thus, the effect of motivation is crucial to students' achievements because even people with the required knowledge, skills, and abilities will perform poorly if they are not motivated to devote their time and effort to work (Harris in Milapo, 2001:29). The purpose of the study is to explore researches and theories concerning EFL/ESL learners' motivation, the role of teachers in students' motivation; how they can initiate and maintain it. Moreover, this study aims to identify strategies obtained from the literature on motivation and suggest motivational techniques appropriate to be used by teachers in Iraq.
\end{abstract}

Keywords: motivation, students' achievement, intrinsic/extrinsic strategies

\section{Introduction}

The efficiency of learning in the classroom not only depends on learner's cognitive abilities alone but on other affective factors as well. There are several components of EFL teaching- they are: the teacher, the students, and the materials that are used in the classroom. However, there are also other important factors such as: administration, methodology, and learning facilities like libraries, classroom amenities (Issan S.and Gomaa N., 2010). All of these factors can be enhanced by educational policies and planning, professional development programs and, of course, by means of budgets. Besides, there is one important factor without which other factors might be insufficient. This factor is motivation, the drive which makes students use all learning resources to reach their learning goals. In foreign language learning, Cheng H. F. and Dörnyei Z. (2007) define motivation as the initial engine that brings about learning and later maintains the driving force in the process of learning a foreign language. Motivation is a dynamic stimulus of a person which starts, directs, maintains and evaluates the cognitive and physical processes of learning. Motivation provides learners with driving wishes, desires which trigger them to act in the learning process.

Motivation plays a critical role in the success of learning a foreign language since it's the primary dynamic stimulus that initiates a mental and physical activity and it is the driving force that maintains the desire in the long and exhausting learning process (Al-Mahrooqi R., Shahid A., Cofie C., 2012). Even learners with required knowledge and skills cannot be successful if they are not sufficiently motivated. Motivation is complex, it includes factors such as: value of the task, estimation of the chances of success by students and reasons behind the successes and failures of the task (Dörnyei Z. and Ushioda Z., 2011). There are two important factors that serve as the primary source of motivation for students. One of them is the classroom environment, which is powerful for motivating learners and the other is the teacher, who plays a significant role in motivating students through the opportunity of implementing different motivational strategies.

Because of the crucial role of motivation in foreign language learning, a lot of studies have been carried out during this decade to find out how it influences and enhances language learning. The main studies on students' motivation were influenced by Robert Gardner and Wallace Lambert $(1959,1972)$ who viewed motivation as a social psychological phenomenon and as a tool for intercultural communication. Motivation to learn another language results from the learners' perception of getting to know about other communities and, in some cases, integrating in the target culture. However, they did not mention classroom implications and teachers' role in promoting effective teaching practices. During the subsequent years, researchers conducted various studies on motivation focusing on the cognitive aspect of motivation, prevalent psychological theories of motivation, and classroom and teacher factors of motivation.

This current paper aims to find out motivational strategies, obtained from the literature, that teachers can employ to motivate their L2 learners in Iraqi context. On many occasions, students become demotivated to learn a foreign language after facing several obstacles. However, there might be certain motivational strategies that can be used by teachers in Iraq to overcome these obstacles and motivate learners and trigger their desires again in order to maintain the learning process successfully in most difficult situations. In this regard, I think teacher motivation is also one of the main variables in the use of motivational strategies in the classroom, since a motivated teacher will do his/her best to 
use strategies to motivate his/her students. This paper analyzes the importance of teacher motivation and discusses the role of teachers in motivating learners and presents motivational strategies that can be implemented by teachers in the language classrooms.

\section{Studies on Language Learning Motivation}

Studies in the foreign language motivation date back to the middle of twentieth century and were later developed by Lambert and Gardner. According to Gardner (1985) there are three key components of L2 motivation: 'motivational intensity or effort", "desire to learn the language" and "attitudes towards learning the language" (Dörnyei Z. and Ushioda Z., 2011, p. 41). He further identifies two primary orientations which he called goals that give rise to motivation in his research. These are: "an integrative orientation" and "an instrumental orientation". The integrative orientation is the desire to interact with the target language community whereas the instrumental orientation is the practical opportunities for learning a new language such as: to find better jobs or get promotion. However, there are other orientations to language learning such as travelling, looking for new friendships and acquiring knowledge associated with instrumental orientations (Clément R. and Kruidenier B. G., 1983) that motivate learners to master their skills in the foreign language. Later years (Dörnyei, 1994, p. 275) categorized language motivation into three levels: language level, learner level and learning situation level. The language level means the benefits and values associated with the target language. The learner level refers to the learners' characteristics in the classroom. The learning situation refers to the factors such as the teacher, teacher's personality, teaching methods, classroom environment. All these three levels independently play significant roles in language learning motivation.

Another important theory of motivation is Self-determination Theory developed by Deci and Ryan in 1985-1995. This theory emphasizes providing learners with self and intrinsic drives to behave in the desired ways. This theory has three steps to motivation in accordance with the increase of self-motivation. First one is amotivation, which is when a learner thinks that there is no point in doing something since he/she understands that the goal is not realistic or achievable and beyond his/her power (Dörnyei, 2001). According to Ryan R. M. and Deci E. L. (2000), amotivated language learners think that they are wasting their time since they don't think learning another language is important or they don't think that they will be successful. This view is also in agreement with Expectancy and Value Theory which claims that individuals are usually motivated to strive for their best in their work situation when they believe there is a probability of success and their performance will be rewarded (Vroom, 1964). Therefore, it's important to keep in mind that goals and objectives set for students must be involving and challenging but still achievable. Amotivation is different from demotivation in the way that demotivated students were once motivated but because of some other reasons their motivated behavior is reduced towards to the task so they become demotivated (Dörnyei, 2001)

Second is extrinsic motivation. It's when there are external factors pressurizing to learn a foreign language. Those factors can be a reward or other means recognition. Extrinsically motivated students learn a foreign language because of the job opportunities or because of the recognition, reward or praise they receive from their teachers, peers or parents. On the other hand, when the external factors are removed, the learner might become demotivated to learn the language (Noels K. A., Clement R. and Pelletier L. G., 2001).

Third is the intrinsic motivation. It stems from the internal factors and it is generated by the doer him/herself. Certain behavior is performed by a person because it gives him lher pleasure and a person gets a psychological reward rather than physical. Intrinsically motivated learner studies hard to learn since it gives him/her the feelings of satisfaction through achieving a goal, developing new knowledge, and exploring new ideas. Ryan R. M. and Deci E. L. (2000) state that sense of "competence, autonomy and relatedness" lead to the feelings of satisfaction in intrinsic motivation.

Gardner R. C. and Lambert W. E. (1959) discovered that the aptitude for languages is not the only factor for the effective foreign language learning. They assume that achievement in L2 depends on the way a learner is able to adopt certain cultural behavior patterns of the target language speakers. In this regard, language teachers are the primary source of students' motivation since they present the target language culture along with the language in the classroom. According to Whitaker (2004) the primary variable in the classroom is the teacher not the student. Thus, teacher motivation is viewed by many researchers as being the most crucial variable in student motivation in second language acquisition (SLA). Atkinson (2000) conducted a research on teacher-student motivation and concluded that the direct relationship existed between them. Other researchers tried to find how a language teacher can enhance students' motivation for excellence in L2 learning. They came up with results that what influences learners' motivation positively is when the language teacher acts as a facilitator, as a consultant, a mentor and a supporter in language classes. Students are involved in activities in the language classes since their motivation is enhanced by their teacher playing the roles that are mentioned above. Many other studies also indicate teacher-related factors that motivate students to learn. According to Williams M. \& Burden L. R., (1997) there are several teacher-sourced factors that might influence learners' motivation such as: interaction between teacher and student, rewards, feedbacks, punishment, praise, etc. Dörnyei Z. \& Csizér K., (1998) suggested three components of teacher related motivation: teachers' behavior, personality and teaching style. All of which undoubtedly influence students' motivation to learn another language.

\subsection{Motivational Strategies}

To enhance students' motivation, teachers try to use motivational strategies in the classroom. Motivational strategies are defined as the deliberate interventions used by teachers to initiate and maintain students' motivation and protect it from distractions (Dörnyei Z. and Ushioda Z., 2011) However, there is a variety of motivational strategies which can be 
benefited from in the language learning classrooms. So, teachers may employ specific strategies from their experiences or from the researches that fit into their specific situations. For example, Schacter (1999) recommends employing technology in the classroom environment to motivate students to engage in the activities to be able to achieve learning goals, while other researchers recommend having good relationship with students to increase students' motivation. Dörnyei Z. and Csizér K. (1998) recommend 10 commandments to be used by teachers to increase students' motivation. Thus, it's the teacher's responsibility to try to find strategies and adopt them or devise new ones to use in the classroom. Dörnyei (2001) states that at least there would be one among many strategies that will be effective in any case. Factors, that play a significant role in foreign language acquisition, along with the teachers' motivational strategies, are teachers' behavior, rapport with students, classroom environment and course materials.

When external variables to motivate learners are insufficient, it would be better to direct our attention to psychological variables of motivation. Most of the time students are kept responsible for their own motivation with their interests and efforts. However, in this study we analyze students' motivation from the teachers' perspective, how to inspire learner motivation, how to keep them motivated and to point out possible strategies that would fit Iraqi context. In Iraqi universities there are distinctive challenges related to students' motivation that are encountered by many English language teachers. Students normally learn English because it is the medium of instruction in Iraqi universities. Furthermore, there are other reasons that students learn English for such as: migration, better jobs, social media, the Internet, etc. The most important challenges, faced by EFL teachers in Iraq, are cultural and linguistic differences between the two cultures and languages which might damper learners' motivation. Another important challenge is the political instability in the region. Since the Gulf War, political situation has never been stable which has had a great influence on the motivation of language learners. On the other hand, this issue might motivate some learners to learn English to seek refuge in English speaking countries. Taking into consideration aforementioned challenges it becomes teachers' responsibility to motivate learners to achieve the learning objectives.

\section{Promoting Motivation in EFL Classrooms}

\subsection{How to generate basic motivational conditions?}

Teachers cannot generate motivation successfully if certain conditions are not applied in language classes. There are three important variables in generating those conditions. They are "the teacher, the classroom atmosphere and the learner group with group norms" (Dörnyei, 2001, p. 31). Undoubtedly, the first most important variable in generating motivational condition is the teacher. The study conducted by Dörnyei and Csizer (1998), on 200 Hungarian teachers, revealed that teachers' behavior was the most important tool for students' motivation. Similar results were also found by different researchers in different cultures. For example, Al-Mahrooqi R., Shahid A. and Cofie C. (2012) conducted a research on Omani teachers of English and found the most important motivational strategy was the teacher behavior in the classroom. It shows that teachers' behavior is the key feature for the students' motivation and it plays a critical role for students' engagement in classroom. Whatever a teacher does in the classroom can have influence on students' motivation positively or negatively and that will affect their academic achievements. There are several teacher characteristics that can play a significant role on students' motivation and academic achievements as well. One of them is the teacher enthusiasm. Enthusiastic teachers love what they do and it can be seen through their dedication, commitment and passion for teaching. American psychologist Csikszentmihalyi (1997) argues that students might find this dedication funny, but, in fact, they admire it. Dörnyei (2001) states that this enthusiasm later becomes infectious and causes students to have the same feeling towards the subject. Therefore, it is imperative to share the reasons why you are so interested in the topic and to talk about the values attached to learning another language such as: enriching your knowledge, satisfaction and pragmatic gains.

Another important teacher-based factor for generating motivational condition is caring about the students and showing that you are not there for salary. It's very important that the students should feel that the teachers really care about them and they are ready to do everything so that their students can learn successfully. This can be done through several ways such as: showing personal interest in students' personal issues, offering constant help, listening to their problems and showing concern or offering extra instructional programs when needed. However, if students feel that the teacher doesn't care, in this case, even the most enthusiastic and passionate students are likely to become demotivated and demoralized (Dörnyei, 2001). Moreover, Dörnyei (2001) argues that teachers should be available mentally and physically within the students' reach. Although most teachers are overloaded and pressed for time, they can find extra time for their students by joining their students in lunch time, in the playground, by dedicating office hours to students or by giving e-mail and phone number for times when students need assistance.

We have seen above that teachers' behavior can play significant role for creating motivational conditions in the classroom. Therefore, it is important to create a classroom environment where trust and respect of learners are guaranteed (Allison J. and Halliwell S., 2002). Teachers can develop such respect and trust by being interested in learners' personal matters, developing close ties and having warm personal interaction with the students. Such teachers are more likely to inspire the students in learning matters than those who have no personal interest in learners' issues (Dörnyei, 2001).

It is also important for the teacher to show high expectation about students' achievements. In a study conducted by Rosenthal R. and Jacobson L. (1968), it was revealed that teachers who labeled students as "intellectual bloomers" showed significant difference in test scores whereas at the beginning of the experiment they were similar in every respect. Thus, if a teacher believes that his/her students can accomplish their learning objectives successfully, they will 
also begin feeling in that way which will eventually yield good results. On the other hand, if you don't have high expectation about your students' achievements, they will probably feel it and produce low achievements. In other words, low expectations lead to low achievements. Therefore, having high expectation might lead to higher academic achievements.

Another important characteristic of a teacher is always being in touch with students' parents. Good relationship with parents can be a powerful ally in student motivation. Brobhy (1987) argues that one of the best characteristics of a successful teacher is when he/she gets in touch with parents and keeps them informed about the students' progress and involves them in decision making process. Parents always like such teachers since they care about their children's success and they are always happy to see the teacher acting for the interest of their children. Gardner (1985) states that parents play a passive role in L2 learning. He further argues that this passive role can be very powerful when parents encourage academic process of their children. However, when the parents have negative attitudes towards the L2 community, this will cause children to lose their motivation to learn the target language. The relationship with parents might not apply in adult education in some cultures but in Iraqi culture, which is rather conservative, it has its effect even at university level.

Pleasant and supportive classroom atmosphere is second basic motivational condition. In a language class, learners have difficulties producing even simple sentences when they focus on pronunciation, grammar and other linguistic contents at the same time. This might cause language anxiety in the classroom. Dörnyei (2001) states that students' anxiety is the most powerful factor undermining their motivation and hindering language learning achievements. There is a consensus among researchers about the solution of this debilitating anxiety. The solution is creating relaxed and supportive atmosphere in the classroom. Dörnyei (2007, p.41) mentions three components of physiological environment of the classroom; "teacher's rapport with the students, students' relationship with each other and norm of tolerance". In a tolerant classroom, students can take risks to communicate in the target language; since they feel safe from embarrassment and their mistakes won't be laughed at and criticized, where realizing mistakes is a natural part of learning. In such an atmosphere students are encouraged to express their ideas freely on different issues that will in turn increase their self-confidence and motivation. Another tool for creating relaxed and supportive classroom atmosphere is the use of humor (Dörnyei, 2001). This might also decrease anxiety and cause relaxed atmosphere where students can take risks readily. However, physical environment of the classroom is also a distinctive feature for language motivation (Dörnyei, Creating a motivationg classroom environment, 2007). The posters, flowers, display boards might serve for relaxed atmosphere in the classroom as well.

The third basic motivational condition is related to creating a cohesive learner group with constructive group norms (Dörnyei, 2001). Many socio-psychological studies show that the group has a significant influence on the member's behavior. A cohesive learner group is formed when learners stick together to provide support to each other. Because of the shared interest and responsibility in a cohesive class groups, group members encourage and support each other which makes the task more enjoyable and consequently leads to the improvement of students' motivation. Teachers should promote cohesive groups by interaction and cooperation among the students and by implementing whole-group tasks and by extra time spent together. However, group norms must be involving and must be discussed by teachers and also by students in order to yield more effective results (Dörnyei, 2001). Finally, the teacher and the students should have consensus on a particular set of rules and the consequences if rules are broken in the classroom. Teachers' attitude is also important towards these group norms. If the teacher is not serious about the established norms, this might give a negative message to students which will later cause them to disobey the rules since they are not taken seriously by their teacher. Hence, it's important to observe the rules continuously and make sure established norms are followed by the group members. Moreover, it would be better if the rules are monitored and observed by the learners. Any violation should be addressed by the members of the group rather than by the teacher and the group should take charge of and cope with such violation.

\subsection{Generating initial motivation}

Teachers always dream about having highly motivated students in their classes who are intrinsically motivated by their internal drives and who don't need many stimuli from the teachers to learn and reach learning goals. However, not all learners are ready to absorb morsels of wisdom and have curiosity and desire to learn the subject. It is because the learners perceive that they spend best years of their lives in the school building and doing their homework at home. It was found that school year was seen the least rewarding activity among adolescents and was described as boring and not enjoyable (Schnider B., Csikszentmihalyi M. and Knaut S., 1995). Therefore, it is the teachers' responsibility to generate students' interest and enjoyment to learn by focusing on intrinsic, integrative and instrumental values of the target language (Dörnyei, 2001). This can be achieved by providing students with enjoyable tasks, technology-based learning and variety of activities that address students' interest. To do that, it is imperative to build good relationships with students to get to know them better so that teachers might know what students are interested in most. Teachers can enhance students' motivation through integrative values by familiarizing learners with the target language community, inviting a native speaker to the classroom, improving cross-cultural awareness, using authentic materials, organizing trips to the target language community, etc. There are other orientations to language learning such as travelling, looking for new friendships and acquiring knowledge associated with instrumental orientations (Clément R. and Kruidenier B. G., 1983) that can be used to motivate learners to master the foreign language. 
The second important factor that can be used to generate students' motivation is promoting students' expectation of success (Dörnyei, 2001). As it was mentioned in the literature, it is has been proved that students are motivated to study when they believe the success is achievable. According to the Expectancy and Value Theory developed by Victor Vroom (1964), individuals are usually motivated to strive to their best when they believe there is a probability of success. Therefore, it's important to keep in mind that goals and objectives set for students must be involving and challenging but still achievable. Students' expectancy of success can be enhanced by giving clear instructions and enough time for preparation, providing constant help if necessary, removing potential problems to learning, promoting peer-group work and explaining how success can be achieved (Dörnyei, 2001).

Goal-orientedness is another key determinant for generating students' initial motivation (Dörnyei, 2001). In most of the cases, teachers comply with the official syllabus specifications that do not match learners' own goals. Sometimes, students do not even understand why they are involved in some learning activities. Therefore, teachers should try to orient learning objectives with the students since official goals, most of the time, do not make sense for students as they do not match learners' expectations and learning objectives. Thus, it is imperative to discuss each individual's specific learning goals so that the teachers can outline common class goals. Undoubtedly, goals affect learners' performance, thus, it is crucial to formulate class goals by negotiating with the learners for the whole group rather than expect them to fulfill these goals.

Another important strategy to generate motivation is to make the course materials relevant for learners' needs. In most cases, students become demotivated when they are forced to learn something that doesn't seem significant in their lives. Passe, (1996) argues that state policies and standardized tests put enormous pressure on teachers to cover the curriculum by rushing through the required content which causes loss of students' motivation and interest to learn. Moreover, in most countries, teaching communicative skills fail because the teachers have to stick to the curriculum in order to prepare students for the standardized language exam as quickly as possible. In order to make the ready-made curriculum motivating to the learners interest, Dörnyei, (2001) suggests relating materials to the life experiences and backgrounds of the learners. To do so, it is imperative to conduct need analysis by investigating students' reasons of learning English, their hobbies and interests so that to have the knowledge about L2 learners and then find out topics on the basis of the students' needs, only after that design the course to make the lessons more appealing to them. Otherwise, students cannot be motivated if they don't see any points worth learning that can be applied in their lives.

Most of the certain beliefs of language learning can be incorrect. For example, some learners believe you can learn a language in the host country but other may believe you can learn it better when you start as a child. Some might believe grammar is important, while others believe fluency is more important than grammar. Dörnyei, (2007) states that the list is endless and those unrealistic beliefs might hinder language learning. Thus, teachers should provide learners with realistic beliefs about language learning. Unrealistic beliefs might cause disappointments in their expectations that will lead to the loss of motivation to learn. Therefore, teachers should explain the difficulty of language learning, personalize language learning, give strategies from their own experiences about how a language is best learned and find out specific ways that can contribute to success.

\subsection{How to protect learners' motivation?}

To maintain and protect motivation, it is crucial to make the learning activities stimulating and enjoyable. This can be achieved by breaking the monotony by providing interesting and challenging tasks in a motivational instructional manner and involving the learners in the activity. If the monotony of learning is broken the learners will definitely participate in the learning activities since the tasks are not boring any longer. According to Anderman E. M. and Anderman L. H. (2010) learning tasks are the biggest components of motivation. This kind of involving atmosphere can be created by implementing different approaches and techniques with various materials and presentations in the classroom. For example, it might be a good idea to start the lesson with a short game or a visual presentation and during the long session it would be good to have a short break involving some sort of movement or short games to attract learners' focus on the subject again. Sometimes, it's also a good idea to do something different that learners don't expect. The most important thing here is the students' involvement in the activity. In order to make the learning enjoyable and stimulating teachers should to try to create an atmosphere where the learners participate actively.

Another important way to maintain learner motivation is to equip learners with effective learning strategies. Considering individual differences of the learners, teachers should provide them with a set of learner-specific strategies that will help them maintain their motivation and accomplish their specific learning goals. Teachers can also promote learners to put challenging but still achievable short-term goals for themselves, and they should monitor the process and give feedback. Alisson (1993) recommends goal-setting techniques for demotivated and reluctant language learners. For example, teachers can set potential goals according to learners' level of commitment and ask every learner to devote themselves.

Promoting self-confidence is another factor for maintaining learners' motivation. According to Banya K. and Cheng M. (1997) confident learners are less anxious in the classroom environment which can lead to mastery in learning a foreign language. Since language anxiety is one of the debilitating factors that reduces motivation and achievement in foreign language learning, it is important that the teachers help students diminish anxiety-provoking factors in the classroom. This can be done by organizing group/ pair work, focusing on their accomplishments, recognizing their anxiety and supporting them to overcome it. Moreover, Dörnyei Z. and Ushioda Z. (2011) also emphasize that students cannot 
achieve high goals if they don't believe in their own abilities. Considering this, it is significant that teachers should inculcate in learners "what they can do rather what they cannot do" spirit.

Learner motivation can also be protected when they feel a positive social image. No learner will take the risk to do a task which will put his face in jeopardy. Since it is highly important for learners to be accepted and valued in their groups, they try to demonstrate positive social image in their community. Teachers should protect their students' social image by establishing safe classroom atmosphere, protecting their face by avoiding comparison, criticism and humiliation in the classroom (Dörnyei Z. and Ushioda Z., 2011). When needed, criticism should be constructive and delivered in private.

Another important strategy that has been researched in educational psychology is learner autonomy. Autonomy has been highlighted by self-determination theory as taking more responsibility of one's own behavior, when one has freedom to choose and to have choices rather than being forced to behave according to someone else's wishes. The easiest way to ensure that learners value the task is to foster their autonomy and give freedom to make their own choices about what, when and how to do things. Thus, teachers should promote learners' autonomy in various ways including involving learners in organizing the learning process and materials selection, giving them authority in teaching roles and project work (Dörnyei Z. and Ushioda Z., 2011). However, learner autonomy can bring some risks such as: conflicts and misunderstanding between the teacher and the learners, wrong choices made by learners, misuse of trust, etc. Dornyei Z. and Malderez A. (1997) state that teachers should realize that those risks are the natural part of autonomous learning, thus, they should be ready to deal with them.

\section{Implications for EFL Teachers In Iraq}

To raise students' motivation EFL teachers in Iraq are recommended to:

- Constantly remind their students about pragmatic benefits of proficiency in English. Awareness in this respect should be reinforced in order to make students more motivated. Since finding good jobs is problematic in the country, knowing the English language can definitely open new job opportunities for the learners.

- Have a good relationship with the learners. One of the obstacles to having such a rapport is that, in Iraq, most teachers act in an authoritarian way to maintain discipline in the classroom. However, it arouses negative feelings in students towards the teacher and consequently decreases their motivation. In order to have good relationships with students, teachers should adopt the authoritative role for themselves. They should have clear boundaries with the regulations, but at the same time be responsive to each student's needs, personal issues and emotions. Unfortunately, most teachers are overloaded and they have about 6-8 lessons a day, but they can find extra time for their students by joining them during the lunch time or in the playground and by encouraging learners to phone them or write e-mail letters when necessary. Finally, this kind of teacher behavior can create a good rapport with the learners.

- Create a pleasant and stimulating classroom atmosphere. The literature shows that tense classroom atmosphere might undermine learning process and motivation, while a safe classroom, where students express themselves freely without being ridiculed, can positively affect the learning process and their motivation. Unfortunately, in each classroom there are about 30-50 students which makes it extremely challenging for teachers to control the class, let alone teach the subject. In such classrooms, learners need teachers who are enthusiastic and who actively engage students in the learning process. Teachers can use several strategies to motivate their students even in these conditions. For example, they can provide support and encourage them to be a successful learner, reshuffle the students so that weaker learners sit next to stronger ones who will act as role models for the former, fill the classroom with positive messages and quotes from their national thinkers and philosophers, create an atmosphere where each learner can take risks to communicate realizing that mistakes are the natural part of learning, encourage them to be self-confident learners, provide constant feedback and allow students to talk with the teacher privately about any issue students think of. Moreover, teachers can also make students motivated when they use various presentation formats, interesting topics and other means of visual and auditory materials.

- Make the course materials relevant to learners' needs. In Iraqi schools, because of the predefined curriculum, most teachers rush through the required content which causes learners to lose their motivation. Normally, all people display inborn curiosity to discover their environment, so they are likely to find the learning practice pleasant, nevertheless, curiosity is reduced by such unavoidable factors as curriculum content, obligatory school attendance and grades. Therefore, teachers should investigate the learners' interests and adopt the syllabus on the basis of their interests or make some changes so that they can find the lessons appealing and intrinsically pleasant to them. It would be beneficial if teachers incorporate with learners in this process when defining the criteria for the learning goals. This kind of environment can also be created if learners have autonomy. Autonomy can be promoted if the teacher gives choices and involves the students in deciding, designing and running the English course. This approach most probably will help them value the task which will ultimately raise their motivation.

- Raise students' integrative orientations towards English. There are some prejudices against the western culture and that affects students' motivation to learn English. In order overcome this bias a teacher can provide opportunities for learners to get to know the L2 culture and people better. Although it is difficult to find native speakers of English to communicate with in Iraq, teachers can familiarize learners with the target language 
culture by using authentic materials, inviting native speakers if possible, organizing trips to the target language community. These orientations will definitely increase students' motivation to learn English.

- Encourage students to work in groups /pairs. This helps timid/ inhibited learners take an active part in accomplishing tasks and support each other. Taking into consideration peculiarities of this culture, teachers should exercise caution when putting girls with boys in the same group at universities since almost at all secondary and high schools they study separately. Thus, group norms should be established carefully. They should be discussed prudently and accepted by the majority of the members in order to be profitable and longstanding. Teachers should not dictate the group norms, if so; it will not become a group norm and will become ineffective.

- Have regular contacts with students' parents. As this is a conservative/ traditional culture, even at a university level teachers' relationship with parents has a positive effect on students' motivation and achievements. As we already mentioned earlier, successful teachers are the ones who stay in contact with parents and keep them informed about the students' progress and include them in the decision making procedures. Moreover, parents can play a very influential role when they encourage their children in language learning. As it was discovered in learner motivation literature that when parents have negative attitudes towards the L2 community, this might negatively affect students' motivation to learn the language.

- Distance themselves and their students from political and factional conflicts. Iraq, being a cosmopolitan country, contains different nationalities and religions and political parties. Taking into account the sensibility of these people's towards the issues like tribal conflicts, religion and politics, teachers should exercise caution in the classroom and they should try to lessen students' engagement in factional conflicts and political activities or they should keep them away from such activities and confrontations which do not contribute to their motivation and language learning practices.

\section{Conclusion}

In this paper, I tried to point out some influential theories concerning language learning motivation and the influence of teachers in fostering students' motivation. The literature, obtained from different researches, once again demonstrated that teachers play a significant role in enhancing learners' motivation. Therefore, it's the teachers' job to generate strategies to keep the students motivated towards the foreign language. To arouse the interest of the students to study the language, teachers should conduct the needs analysis to find out why they need to learn the language and talk about pragmatic gains and integrative values that the knowledge of the target language can bring about. This will help arouse their intrinsic values, which is their internal interest and curiosity for the language learning activity. Moreover, teacher motivation is also important because such teachers are likely to involve students in the learning tasks and inspire their enthusiasm and motivation. Thus, Iraqi EFL teachers can find this paper beneficial to integrate the strategies, use the appropriate ones in their classrooms and help learners reach the learning objectives effectively.

\section{References}

Alisson, J. (1993). Not Bothered? Motivating Reluctant Language Learning in Key Stage 4. London: CILT.

Allison J. and Halliwell S. (2002). Challenging classes: Focus on pupil behavior. London: CILT.

Al-Mahrooqi R., Shahid A., Cofie C. (2012). Analyzing the Use of Motivational Strategies by EFL Teachers in Oman. Malaysian Journal of ELT Research, 8(1), 36-72.

Anderman E. M. and Anderman L. H. (2010). Classroom Motivation. Upper Saddle River, NJ: Merrill.

Atkinson, E. S. (2000). An investigation into the relationship between teacher motivation and pupil motivation. Educational Psychology, 20(1), 45-57.

Brobhy, J. E. (1987). Motivating Students to Learn. Boston: McGraw-Hill.

Cheng H. F. and Dörnyei Z. (2007). The Use of Motivational Strategies in Language Instruction: the Case of EFL Teaching in Taiwan. Innovation in Language Learning and Teaching, 1(1), 153-174.

Clément R. and Kruidenier B. G. (1983). Orientation in Second Language Acquisition. Language Learning: AJournal of Research in Language Studies, 33(3), 273-291.

Csikszentmihalyi, M. (1997). Intrinsic motivation and effective teaching: A flow analysis. In J. L. Bess, Teaching Well and Liking It: Motivating Faculty to Teach Effectively (pp. 72-89). Baltimore: John Hopkins University Press.

Deci, E.L. and Ryan R.M. . (1985). Intrinsic Motivation and Self-Determination in Human Behavior. New York: Plenum Publishing Co.

Dörnyei Z. \& Csizér K. (1998). Ten commandments for motivating language learners: Results of an empirical study. Language Teaching Research, 2, 203-229.

Dörnyei Z. and Ushioda Z. (2011). Teaching and Researching Motivation. Harlow, England: Pearson Longman. 
Dörnyei, Z. (1994). Motivation and Motivating in the Foreign Language Classroom. The Modern Language Journal, 273-284.

Dörnyei, Z. (2001). Motivational Strategies in the Language Classrooms. Cambridge: Cambridge University Press.

Dörnyei, Z. (2007). Creating a motivationg classroom environment. In Cummins, \& J. C., International Handbook of English Language Teaching (pp. 219-231). New York: Springer.

Gardner R. C. and Lambert W. E. (1959). Motivational Variables in Second Language Acquisition. Canadian Journal of Psychology, 13, 266-272.

Gardner R. C. and Maclntyre P. D. (1993). A student contribution to second language learning. Part 2: Affective variables. Language Teaching , 26, 1-11.

Gardner, R. C. (1985). Social Psychology and Second language Learning: The Role of Attitudes and Motivation. London: Edward Arnold.

Harris. (1977). Human Resource Management. A Practical Aproach. Forth Worth: Harcourt Brace College Publishers.

Issan S.and Gomaa N. (2010). Post Basic Eduction Reforms in Oman: A case study. Literacy Information and Computer Education Journal, 1(1), 19-27.

Milapo, L. T. (2001). 'Performance Enhancement in the Civil Service: A Comparative Analysis of the use of HRM Tools in Uganda, Zambia and Zimbabwe', Master's Research Paper. Institute of Social Studies, Erasmus University.

Noels K. A., Clement R. and Pelletier L. G. (2001). Intrinsic, Extrinsic and Integrative Orientations of French Canadian Learners of English. Canadian Modern Language Review, 57, 424-444.

Passe, J. (1996). When Students Choose Content: A Guide to Increasing Motivation, Autonomy and Achievement. thousand Oaks, CA: Corwin Press.

Rosenthal R. and Jacobson L. (1968). Pygmalion in the Classroom. New York: Holt, Rinehart and Winston.

Ryan R. M. and Deci E. L. (2000). Intrinsic and Extrinsic Motivation: Clasic Definitions and New Directions. Contemporary Educational Psychology, 25, 54-67.

Schnider B., Csikszentmihalyi M. and Knaut S. (1995). Academic challange, motivation and self-esteem: The daily experience of students in high school. In M. T. Hallinan, Restructuring Schools: Promising Practices and Policies (pp. 175-195). New York: Plenum.

Solak E. and Bayar B. (2014). The factors influencing the motivational strategy use of non-native English teachers. International Journal of Education and Research, 2, 1-12.

Vroom, V. H. (1964). Work and motivation. San Francisco, CA: Jossey-Bass.

Whitaker, T. (2004). What Great Principals Do Differently. Larchmont, NY: Eye On Education Inc.

Williams M. \& Burden L. R. (1997). Psychology for language teachers. A social constructivist approach . Cambridge: Cambridge University Press. 